\title{
¿UNA «CONVULSIÓN GENERACIONAL»? JÓVENES, ETIQUETAJE Y ESTIGMA EN LA REBELIÓN DE OCTUBRE
}

\author{
YANKO GONZÁLEZ ${ }^{1}$
}

\begin{abstract}
RESUMEN
El presente trabajo - basado en fuentes teóricas, archivos de prensa y observaciones etnográficas exploratorias - busca reflexionar sobre aquellas interpretaciones tempranas y por momentos hegemónicas — como las del abogado y rector Carlos Peñasobre la rebelión de octubre como una «convulsión generacional», provocada y conducida fundamentalmente por jóvenes. A partir de ello, el artículo analiza y discute el rol de las autoridades intelectuales articuladas con los medios de comunicación de masas en la construcción de etiquetas y estigmas sociales juveniles y el potencial teórico y derivas heurísticas de la noción de generación para entender la revuelta iniciada el 18 de octubre de 2019.
\end{abstract}

PALABRAS CLAVE: JÓVENES, REBELIÓN SOCIAL, GENERACIÓN, ETIQUETAJE, ESTIGMA.

${ }^{1}$ Doctor en Antropología Social y Cultural, profesor titular del Instituto de Historia y Ciencias Sociales de la Universidad Austral de Chile. Correo electrónico: ygonzale@uach.cl. Algunas ideas de este trabajo fueron esbozadas oralmente en el foro «Sujetos históricos de estallidos sociales», organizado por Radio UACh y realizado en la Casa Central de la Universidad Austral de Chile el 20 noviembre 2019. 


\title{
UMA «CONVULSÃO GERACIONAL»? JOVENS, ETIQUETAGEM E ESTIGMA NA REBELIÃO DE OUTUBRO
}

\begin{abstract}
RESUMO
O presente trabalho - com base em fontes teóricas, arquivos de imprensa e observações etnográficas exploratórias - procura refletir sobre aquelas interpretações iniciais e por vezes hegemônicas - como as do advogado e reitor Carlos Peña - sobre a rebelião de outubro como uma «convulsão geracional», provocada e conduzida principalmente por jovens. A partir disso, o artigo analisa e discute o papel das autoridades intelectuais articuladas com a mídia na construção de etiquetas e estigmas sociais juvenis e o potencial teórico e derivas heurísticas da noção de geração para compreender a revolta iniciada no dia 18 de outubro de 2019.
\end{abstract}

PALAVRAS-CHAVE: JOVENS, REBELIÃO SOCIAL, GERAÇÃO, ETIQUETAGEM, ESTIGMA.

\section{A «GENERATIONAL UNREST»? \\ YOUNG PEOPLE, LABELLING AND STIGMA IN OCTOBER UPRISING}

\begin{abstract}
The present work - based on theoretical sources, press archives and exploratory, ethnographic observations - aims to reflect on those early, even sometimes hegemonic interpretations about the October uprising, as the one stated by lawyer and Dean Carlos Peña, as a «generational unrest» mainly arisen and led by young people. From these grounds, the article analyzes and discusses the role of intellectual authorities and mass media in the construction of youth social labels and stigmas, and the theoretical potential and heuristic drifts of a notion of generation to understand the uprising started on October 18th, 2019.
\end{abstract}

KEYWORDS: YOUNG PEOPLE, SOCIAL UPRISING, GENERATION, LABELLING, STIGMA. 


\section{INTRODUCCIÓN}

Una y otra vez, los medios de comunicación de masas recortaban, iteraban y superponían las mismas imágenes. Todas parecían ya decodificadas políticamente: en ellas, se mostraban pobladores (in)gobernados por una «turba adolescente», «instintiva», sin agenda ideológica ni propósito político. Imágenes - devenidas ya en representaciones - que comenzaron a diseminarse recursivamente a pocos días del viernes 18 de octubre de 2019. Ese día, las y los estudiantes, que habían estado casi una semana saltando los torniquetes del metro en protesta por el alza del pasaje y aguantando la represión y el escarnio, provocaron por largos meses un vacío interpretativo en el mundo político e intelectual de magnitudes inéditas. Con excepción del abogado y rector Carlos Peña, se impuso una inesperada mudez teórica y, junto a ella, el pánico del establishment y los mass media de despertar de súbito en un mundo extraño, donde los adultos preguntaban y solo los «niños» respondían. Es decir, jóvenes que, en su «caos», «anomia y espasmo», hacían realidad los mayores demonios y las peores pesadillas de la sociedad adulta conservadora: la temida fusión orgiástica y festiva de las nuevas generaciones con el «lumpen poblacional» para saquearles o quemar todo.

El presente artículo busca analizar aquellas lecturas y representaciones tempranas y por momentos hegemónicas, sobre la rebelión de octubre como una «convulsión generacional», de cariz espasmódica y pulsional, provocada y conducida fundamentalmente por jóvenes. A partir de ello, el trabajo analiza y discute la contribución de las autoridades científicas e intelectuales articuladas con los medios de comunicación de masas en la elaboración de etiquetas (labelling) y estigmas sociales referidos a las y los jóvenes. Seguidamente, discute el potencial teórico y derivas heurísticas de la noción de generación profusamente utilizada por dichas autoridades y medios de comunicación — para comprender la revuelta de octubre. Desde el punto de vista metodológico, el artículo se sustenta en diversas fuentes teóricas, archivos de prensa (escritos y audiovisuales) ${ }^{2}$, además de observaciones etnográficas exploratorias y

${ }^{2}$ El corpus analizado fueron las columnas, opiniones y entrevistas - fundamentalmente del rector y filósofo Carlos Peña o referidos a él- aparecidas en periódicos y medios televisivos de distribución y alcance nacional y publicadas entre octubre de 2019 y noviembre de 2020 . 
complementarias $^{3}$. En su conjunto, estas fuentes fueron recabadas, sistematizadas e interpretadas entre octubre de 2019 y noviembre de 2020.

\section{ETIQUETAJE, ESTIGMA Y PÁNICO MORAL}

Como adelantáramos, un intérprete temprano y simultáneo del «despertar de Chile» fue el rector de la Universidad Diego Portales, Carlos Peña, mediático intelectual (además de abogado y doctor en Filosofía, es egresado de un magíster en Sociología) que después de calificarlo como «estallido emocional» de índole «generacional» en múltiples medios escritos y televisados ${ }^{4}$, fue llamado a La Moneda para esclarecer esta nueva realidad juvenil, caótica y «pulsional»al presidente Piñera. Su perspectiva era, en principio, generativa y original (en el contexto del ensayismo sociológico más divulgado sobre el devenir de la realidad chilena postdictadura $)^{5}$, pues se desplazaba desde el tradicional énfasis en los

${ }^{3}$ Dichas observaciones fueron realizadas y registradas en la ciudad de Valdivia durante los meses de octubre, noviembre y diciembre de 2019.

${ }^{4}$ Véase, por ejemplo, la extensa entrevista en televisión abierta concedida por el abogado (Carlos Peña, en Canal 13 de televisión, 21 de octubre de 2019); igualmente sus análisis y opiniones en la prensa escrita como «En la crisis, fortalecer el Estado» (Peña, 24 de octubre de 2019); «El nuevo arcoíris» (Peña, 27 de octubre de 2019); «El debate en estos días» (Peña, 1 de noviembre de 2019); «Viejas Verdades» (Peña, 1 de diciembre 2019); o entrevistas en la prensa escrita, como «No creo haberme equivocado absolutamente en nada» (Carlos Peña, en La Tercera, 4 de enero de 2020).

${ }^{5}$ Valga aclarar que el contexto que le sirve al rector de peana para instalar sus asertos «generacionales» es amoblado por aquellas investigaciones, rastreables en la literatura desde hace años (Hugo Fazio, Manuel Antonio Garretón, Eugenio Tironi, Solimano, Kathya Araujo y Danilo Martucelli, entre varios), que diagnostican que una acelerada modernización capitalista en Chile y una enérgica expansión del consumo habrían generado la aparición y multiplicación de una líquida clase media y, con ella, una revolución de expectativas materiales y postmateriales sin precedentes. En este sentido, para Peña serán los jóvenes los que catalizarán las frustraciones de la sociedad tensionada por esta veloz modernización que, junto al consumo, las nuevas tecnologías y el bienestar conllevan una extrema racionalización de la vida y una individualización creciente («editar» la propia vida), lo que colisiona con una realidad que lo impide, surgiendo un malestar que deviene en estallido. Sobre parte de esta bibliografía, que sugería que el sistema se craquelaría aupado por sus propias limitaciones, el rector como muchos otros antes y ahora- parecía añadir el imperativo de la modulación racional y paulatina de este derrumbe — corrección o autorregeneración-, el que descansaría en el Estado, sus instituciones y, en la práctica, en la habilidad y creatividad política de los sectores progresistas y liberales para torcerles la mano ordenadamente a las oligarquías. 
procesos socioeconómicos y políticos — modernización y legitimidad - a los generacionales $^{6}$. No obstante, dicho desplazamiento al tiempo que sorprendía encallaba en el uso orteguiano de generación y en una nítida noción funcionalista y desviacionista de juventud, de tal modo que una de las primeras voces que piensan la rebelión de octubre se transformará, en tanto «autoridad» científica e intelectual, en un contribuyente específico del pánico moral, la estigmatización y la sanción de la opinión pública hacia múltiples colectivos juveniles, particularmente urbano-populares. «Pienso que el rector Carlos Peña, por algún motivo, les tiene miedo a los adolescentes. Los ve en todas partes», acusaba la destacada escritora Diamela Eltit hacia finales del primer mes de la revuelta (Diamela Eltit, en La Tercera, 25 de octubre de 2019).

En efecto, el resultado de la temprana exégesis de Peña le lleva a calificar al movimiento social como una «convulsión generacional» de cariz pulsional, donde los jóvenes — para él, aquellos nacidos a partir de la década de los 90han transformado sus certezas subjetivas acerca de lo que es verdadero o correcto en «un principio válido de acción social sin ninguna deliberación», decretando como verdad «lo que sienten» como injusto. Así, el estallido no sería ciudadano, sino una mera insurrección de púberes contra las instituciones del Estado, «indigna de llamarse desobediencia civil» por ser apenas un «espasmo violento», una «conmoción emocional» inorgánica, sin proyecto, reivindicaciones, liderazgo o ideas y mucho menos, el légamo que fertilizaría la alteración del modelo, puesto que lo que el rector vio fueron «pandillas, desordenadas, con actitudes carnavalescas, orgiásticas, huyendo de la policía» (Carlos Peña, en Canal 13 de televisión, 21 de octubre de 2019). Similares ideas las fue vertiendo en todas las plazas mediáticas donde se le solicitó su opinión —en su calidad de autoridad intelectual y científico social-, especialmente en la prensa escrita, contrastando el «absolutismo de las propias convicciones» que tendrían las nuevas generaciones con «los grupos medios que han accedido al bienestar y que hoy están presos del temor viendo cómo el entorno de Maipú, Puente Alto, La Florida, que han construido estos años, se derrumba o cae preso de las llamas» (Peña, 24 de octubre de 2019). Seguidamente, su llamado fue al abandono de la «beatería juvenil» por parte de los adultos que han glorificado acríticamente el papel desempeñado por estos colectivos — cuyo sino, parecía decir, es la irracionalidad y la violencia-, a los que hay que poner atajo a través del Estado como poseedor legítimo del monopolio de la fuerza. A comienzos de diciembre, en su columna

\footnotetext{
${ }^{6} \mathrm{Al}$ menos en esos primeros meses y antes de la publicación de su libro sobre los hechos de octubre (Peña, 2020), donde esta interpretación es reforzada por otras.
} 
semanal, henchirá su tesis sobre la «beatería juvenil» glosando, a su modo, $L a$ República de Platón: «Cuando los más viejos condescienden, los profesores en vez de orientar halagan y quienes dirigen imitan a los jóvenes, los ciudadanos empiezan a ponerse alérgico a los deberes. (...) Es el momento de la anarquía o la anomía» (Peña, 1 de diciembre de 2019).

Aunque el empleo del vocablo anarquía resulta eficaz para dibujar y abultar una amenaza, el uso del concepto anomia - apelando directamente a Durkheim, y sobre todo a Merton y Parsons - está destinado tanto a caracterizar sociológica y «autorizadamente» a buena parte de la juventud chilena, como deliberadamente o no- a etiquetarla. Así, según Peña, esta tendría un déficit de «regulación» normativa por parte de la sociedad que oriente su acción; consecuentemente, estaría desviada, es decir, sería un colectivo que padecería un caos debido a la ausencia de reglas o, todavía peor, debido a que sería regida por «otras reglas» que originan desde el aislamiento — «la subjetividad aferrada nada más que así misma» configurando «certezas totales»-, a la contestación recursiva, la violencia o el pillaje. Como se sabe, hasta entrada la década de los 60 , fue literalmente de ese modo en que las ciencias sociales estructuralfuncionalistas norteamericanas tradujeron tanto a las nacientes culturas juveniles como a los movimientos juveniles contraculturales: un «problema». Vale decir, un segmento social «desajustado» por una transición abrupta provocada por el paso de la sociedad tradicional a la moderna y que al mundo adulto le horrorizaba: rebeldes, coléricos, «violentos», «delincuentes». Una promesa de futuro convertida en amenaza del presente que debe ser disciplinada, habida cuenta del colapso de la gobernabilidad, «el no control» de la alienación experimentada por un sujeto o un colectivo que cristaliza una verdadera «cultura» autónoma de normas y valores, centrado en el consumo hedonista y cuyo resultado sería la irresponsabilidad, la confrontación con el mundo adulto, entre otras disfuncionalidades (Parsons, 1963). De tal modo y como a mediados del siglo pasado en Chile, donde las interpretaciones desviacionistas de la acción social juvenil se naturalizaron en los medios (González, 2012), los asertos de Peña son mecánicamente amplificados en la prensa a partir de la estigmatización y la homologación de la condición juvenil a la entelequia de «problema», «tormento»o «drama», pues el rector complementa sus postulados con algunos aportes psico-biologisistas y, al igual que Stanley Hall (1904) o Erik Erikson (1950), parecía decirnos que en estos grupos de jóvenes se libraría una batalla turbulenta entre el instinto y la cultura, signado por una carencia de racionalidad y exceso de pulsión — características que explican las desviaciones de las 
normas - y una fase de confusión — déficit de «orientación»— en la búsqueda de la propia identidad.

Hace algunas décadas, Stanley Cohen (1972) demostró el papel generativo de los mass media y las voces de autoridad - que eligen y transportan - en la construcción de ciertos grupos juveniles como sujetos desviados, como «diablos populares», en la medida que los estereotipan y etiquetan contribuyendo a que el predicamento del estigma se corporice en modelos -y posicionamientos ideológicos, debemos agregar- que informan a la sociedad cuáles son las conductas y roles a evitar, construyendo la legitimidad necesaria para su vigilancia, control y represión. A través del «pánico moral» conducido por los medios de comunicación de masas y vertebrado por las voces de autoridades científicas, políticas y religiosas que diagnostican y sancionan a estos actores juveniles por la «amenaza a los valores sociales» que conllevan (Cohen, 1972: 9), se buscará prescribir las representaciones sobre estos colectivos a partir de un recorte intencionado de hechos y discursos que convierten el caso en universo.

Más allá, Cohen evidenció que este etiquetamiento y pánico moral no solo modifica las representaciones de la realidad, sino que altera, igualmente, la realidad misma, al orientar tanto el comportamiento de la sociedad adulta como de los sujetos juveniles, los que comienzan a actuar y configurar su propia identidad de acuerdo con estas nuevas representaciones. En esta dirección, Peña itera sobre la irracionalidad y la violencia asociadas al mundo juvenil y ello, además de no ser una evidencia neutra, es un estigma que, como la historia nos enseña, rápidamente se transforma en emblema cuando los medios y sus «tributarios pensantes» construyen su origen a través del labeling y el miedo colectivo: un enemigo, un «otro» siempre desviado, amenazante y enorme en número. De ahí lo sintomáticas de las palabras de la Primera Dama de la República al concebir el movimiento como una «invasión extranjera, alienígena» (Cecilia Morel en La Tercera, 22 de octubre de 2019) y la inmediata identificación —irónica y paródica — de las y los movilizados con la figura del extraterrestre. O los rayados que registré en el interior de la oficina de una AFP que acababa de ser saqueada: «La crisis es culpa de lxs anarquistas/y somos caleta» o «tenemos rabia». Esta última, huérfana de consigna, de rúbrica ideológica, desnuda en su sola literalidad emocional, había sido pintada para devolver la ofensa mediatizada con la convicción del orgullo.

Con matices, el abogado mantuvo estos planteamientos, con menos gesticulación pero alojados en dosis diversas y en varios capítulos, en el libro que 
terminará publicando pocos meses más tarde (Peña, 2020). En dicha obra, vuelve sobre algunas ideas ya deslizadas en sus intervenciones en la prensa que resultan paradójicas, al tiempo que lo distinguen como contribuyente directo del labeling mediático. Peña, apelando a Weber $^{7}$, recalca la capitalidad que reviste superar todo «profetismo de cátedra» para el correcto análisis de los hechos de octubre, es decir, aquellas interpretaciones que intentan trajear de análisis científico una mera opinión o postura ideológica. Lo que se traduce en su reiterado alegato en contra de tomar partido y no distancia para la comprensión del estallido (Carlos Peña, en La Tercera, 4 de enero de 2020) y en la asignación de sentido — siempre «interesado»- a la rebelión de octubre, distante y distinta a sus causas «reales». O, en sus palabras: descartar las creencias y «reclamos normativos» como «causa del comportamiento masivo» (Peña, 2020: 69-72), ya la injusticia, ya la demanda social o jurídica de una nueva Constitución política. Lo paradójico es que, salvo por la copiosa cobertura de prensa de sus reflexiones, pocos aspectos parecieron distinguir su custodiada cientificidad del «profetismo de cátedra», neutralidad axiológica o el Wertfreiheit weberiano sobre el mundo juvenil que estaba diagnosticando, es decir, sobre «muchas de las nuevas generaciones», «que han hecho de la performance y de los insultos una protesta política» (Peña, 2020: 151).

Como la literatura juvenológica viene señalando desde hace décadas, a través de la pluralización del concepto de juventud (o sus sinonimias eufemizadas como «nuevas generaciones»), resulta en extremo arriesgado, tanto por sus consecuencias científicas como políticas, postular generalizaciones robustas sobre «la» condición juvenil, desatendiendo no solo las poliédricas modalidades históricas, territoriales, de clase o étnicas que modulan la construcción sociocultural de la edades, sino también y en nuestra contemporaneidad, por la extrema dificultad de abordar con certezas empíricas las dimensiones simbólicas e identitarias en los mundos juveniles, básicamente por la multiplicación, diversificación y fugacidad circular de los tiempos biográficos. ¿Significa eso que estamos condenados a la mudez cognitiva? Por supuesto que no, pero ello nos obliga a tomar serios resguardos teóricos y empíricos para elaborar $\mathrm{y}$, sobre todo, comunicar nuestros resultados si aspiramos a inscribirlos en el lado opuesto del profetismo de cátedra, vale decir, en las antípodas de una «evaluación normativa» de la(s) juventud(es) chilena(s), aquella que juzga la realidad «de acuerdo con ciertos principios independientes a los que se estima valiosos» (Peña, 2020: 156). Así, por ejemplo, glosar a Platón para prescribir el tipo de

${ }^{7}$ Claramente alude a El politico y el científico del sociólogo alemán (Weber, 2012). 
relación formativa, moral o política de la juventud con sus mayores y sus maestros no parece un diagnóstico científico social - como el que sí hizo Margaret Mead (1970) sobre el mismo problema ${ }^{8}$-, sino una homilía o el irritado alegato en contra de las nuevas generaciones como el encontrado en una tablilla de Ur, en Caldea, hace cuatro mil años: «Nuestra sociedad está perdida si permite que continúen las acciones inauditas de las jóvenes generaciones» (Lutte, 1993: 37).

$\mathrm{Si}$ bien conocemos las fuentes secundarias que alimentan las interpretaciones del profesor Peña, desconocemos tanto la metodología, las fuentes primarias o los criterios de selección que utiliza para llegar a sus conclusiones. Como no tenemos posibilidad de conocer todo ello, no nos queda más que reparar en algunos casos de observación que el abogado utiliza para elaborar sus asertos y, de paso, entender algunas consecuencias teóricas y políticas a partir del uso de conceptos basales en su tentativa científica, como el de «generación». Por ello, detengámonos en la destrucción de monumentos públicos ocurrido en esos meses de movilizaciones. A partir del derribo o vandalización de esculturas o estatuas históricas, Peña llega a la conclusión de que otra de las características distintivas de las nuevas generaciones sería la «devaluación del pasado», es decir, «una ruptura de significantes» en la que la juventud no logra unificar el pasado, el presente y el futuro en una misma experiencia, cuyo resultado es que el presente se volvería intenso, próximo a la «experiencia alucinatoria de la euforia» (Peña, 2020: 144). Aunque el propio «recorte» de la realidad sugiere una fijación en aquellos aspectos más destructivos —《anómicos»— y espectacularizados de las movilizaciones, enfrentémoslo — solo a modo de ejercicio - a otros lugares de memoria menos disruptivos: el cancionero de la revuelta. Bajo la noción de «devaluación del pasado», la música incidental de los hechos de octubre resultará para Peña

\footnotetext{
${ }^{8}$ La antropóloga, pionera en los estudios sobre juventud, entenderá y dará evidencias empíricas y teóricas sobre el surgimiento — en los albores de las década de los 60-, de una verdadera «cultura» juvenil situada en una diversidad de respuestas simbólicas y estructurales (de clase, género, territoriales y culturales, entre otras), donde las experiencias sociales de las y los jóvenes son expresadas colectivamente mediante la construcción de estilos de vida distintivos, localizados, fundamentalmente, en los espacios intersticiales de la vida institucional y con grados significativos de autonomía de las sociedades adultas. Para Mead, ello implicó el paso de una cultura «posfigurativa» y «cofigurativa» a una «prefigurativa», en la que los pares - las y los jóvenesreemplazan a los adultos como referentes para la construcción del presente sociocultural, instaurando una ruptura en el entramado de las «clases de edad» sin parangón en buena parte de los últimos siglos en Occidente.
} 
invisible, pues la entonación sistemática por parte de íconos juveniles de la canción popular - y coreado por una porción significativa de los actores sociales movilizados - fueron los antiguos hits contestarios de los años 60 y 80: desde el Derecho de vivir en paz de Víctor Jara y los Blops hasta El baile de los que sobran de Los Prisioneros. Cancionero que se engarzó con los hits insumisos del presente, como Ya van a ver (adaptación de El hijo del botón del argentino Dany Lescano), Cacerolazo de Ana Tijoux o Plata Ta Tá de Mon Laferte, entre otros tantos. Lo propio ocurre con los usos del pasado: muchos monumentos no fueron solo derribados, sino intervenidos para buscar, precisamente en la diacronía, una matriz distinta de comprensión del presente. Un caso ejemplar es el monumento del general Baquedano en la plaza homónima, convertido en un palimpsesto de intervenciones y resemantizaciones. Igualmente lo es el derribo el 29 de octubre de 2019, del busto de Pedro de Valdivia en Temuco, cuya cabeza fue colgada en la estatua de Caupolicán. Así, desde la casuística, podríamos aventurar, con igual vehemencia, una tesis opuesta: más que una ruptura, asistimos a una continuidad de significantes, puesto que no se trata de un mero desprecio «al bulto» por el pasado y la exigencia de un olvido, es recordar por qué esas narrativas inmovilizadas en metal o granito no merecen el recuerdo. Es decir, una vía no marmórea de discutir con el pasado. Volveremos sobre esto.

\section{3. ¿ «UNA CRISIS GENERACIONAL INEVITABLE» O UNA REBELIÓN MULTIGENERACIONAL?}

Ahora bien, parece claro que las inferencias de Peña descansan en otras de mayor alcance, puesto que las rupturas o discontinuidades que ve el abogado se entienden por lo que interpreta como una gran «diferencia de destino» entre los hijos y los padres, lo que la literatura científica conoce como «brecha generacional» y «conflicto generacional». Aunque menos subrayada, suponemos que parte de la evidencia expresiva que tiene el autor para echar mano de la perspectiva generacional se remonta a las movilizaciones juveniles que pusieron en jaque a sucesivos gobiernos de «progreso», activadas y protagonizadas en su mayoría por estudiantes (el mochilazo en 2001, la revolución pingüina en 2006, «el mayo» de 2011 y la primavera feminista en 2018), las que transitan de las reivindicaciones sectoriales a las exigencias estructurales: asamblea constituyente - para una nueva Constitución Política del Estado-y la abolición del orden ultraneoliberal. Pese a que en estas últimas décadas las movilizaciones sociales excedieron en mucho la actoría juvenil-estudiantil (como las de 
Magallanes en 2011 — «segundo puntarenazo»- o las protestas de Aysén y Freirina en 2012, entre otras de orden territorial, indígena o medioambiental), Peña insistirá en postular a las nuevas generaciones como catalizadores y acelerantes principales de la explosiva combustión que acaeció a partir de octubre. En palabras del abogado, los hechos hundían sus raíces en «una crisis generacional inevitable» (Peña, 1 de noviembre de 2019).

Como lo dijéramos, esta tesis descansa en la noción analítica o metodológica de generación (Fuer, 1968) - de larga trayectoria en el pensamiento social para el estudio del cambio social o el espíritu y «actitud» epocal- y en la noción teórica de brecha generacional o generation gap, nacida al calor, precisamente, de las revueltas juveniles que orbitaron en torno a la década del 60, el mayo francés y el surgimiento de la «adolescencia global», y que intenta desentrañar algunos procesos identitarios relacionales, particularmente de las cohortes juveniles y su conflicto o diferencia (Mead, 1970) con el conjunto de la sociedad adulta. Nos limitaremos a señalar otras interpretaciones plausibles de la revuelta a partir de la comprensión divergente de estas nociones empleadas por Peña. Ya por el uso de evidencia contextual tomada de la literatura sociológica chilena de los últimos años-, ya por su «muestreo» de algunos elementos expresivos del estallido, a primera vista pareciera que Peña adhiere más a una versión diltheyana que comteana de generación, es decir, la definida por la «calidad del tiempo» que un grupo humano comparte en términos de influencias sociales, intelectuales o políticas (Dilthey, 1989 [1883]) y no aquella noción biológica, mecánica y cuantitativa de generación y sucesión generacional, exteriorizada del tiempo histórico (Comte, 1998 [1830-1843]). Sin embargo, a partir de su énfasis e interpretación en el problema del relevo y conflicto generacional, el abogado se sitúa pendularmente entre esas dos visiones y termina prendido en una idea cuasi comteana y orteguiana de generación, en la medida que defiende, como el filósofo peninsular, que personas nacidas en una misma época — la década de los 90 para Peña - comparten una misma «sensibilidad vital» opuesta a la generación previa, por lo tanto, el cambio social descansaría en el tiempo que tarda en ser relevada la generación precedente por la nueva en la vida pública ${ }^{9}$. De esta manera, aunque el abogado pareciera concordar con las determinantes histórico-sociales para identificar una generación - lo que hace posible entender fenómenos como la

\footnotetext{
${ }^{9}$ Karl Mannheim - un heredero directo de Dilthey en este punto- será contundente, por cuanto plantea que una comunidad de pertenencia a una generación no se puede comprender y deducir inmediatamente desde las estructuras biológicas (Mannheim, 1993 [1928]: 208-209).
} 
«no contemporaneidad» de los contemporáneos-, arguyendo una acelerada modernización capitalista acaecida en los últimos veinte años que da paso al surgimiento de una brecha política, educativa, comunicativa, relacional insalvable entre mayores y menores, termina afirmando lo opuesto para los sujetos que comparten el mismo «dato» biológico — la edad—, traduciendo esa comunidad de fechas en un comunidad sociocultural - las «nuevas generaciones»- sin distinciones cualitativas internas o fundamentos para que ello sea así. Por lo tanto, en este amplio grupo etario, todos los sujetos juveniles contemporáneos serían considerados por Peña contemporáneos y no cabría ninguna colisión entre biografía y tiempo histórico en cohortes «estructuralmente» distintas en términos de clase, género o, incluso, edad, articuladas de manera importante, como se sabe, por las propias trayectorias educativas (estudiantes secundarios o universitarios, por ejemplo).

Llegados a este punto, no nos queda más que dar cuenta grosso modo de parte de la literatura científico social relacionada precisamente con la multiplicación y diversificación de las biografías juveniles en el presente etnográfico. Como en varios países de Occidente, en Chile han surgido embrionaria, pero sostenidamente, dos «revoluciones biográficas» en las últimas décadas, según colegimos de las encuestas nacionales de juventud (Instituto Nacional de la Juventud, 2000, 2006, 2015, 2018). La primera, hija de la invención y expansión del sujeto juvenil en el siglo XIX y XX (González y Feixa, 2013), está craquelando los cimientos de esta propia «invención»: el cariz transicional, el rito de paso, la búsqueda de autonomía y emancipación; la liminalidad formativa orientada hacia un final (adultez o postliminalidad) que tendría toda condición juvenil. Todo ello se ha desdibujado como epicentro identitario exclusivo del ser joven, en la medida que, por ejemplo, el matrimonio para toda la vida, estable y perpetuo, ha dado paso a la caducidad conyugal y la movilidad amorosa como constante. Lo mismo sucede con el otro motor de adultez: la ruptura del trabajo estable para toda la vida y la irrupción de la flexibilidad laboral y la educación continua como obligación para la sobrevivencia. Así, las relaciones afectivas y el trabajo — dos fuentes de investidura de la y el joven — son precarias y contingentes. Por tanto, la fragmentación y la circularidad colocan al sujeto «una vez adulto biológico» nuevamente en la liminalidad juvenil: mandatado a mantener perpetuamente entrenada la empleabilidad y la emparejabilidad. Es la adulescencia - la adultez perpetuada en adolescencia- o, en palabras de Gil Calvo (2001), la «neoadultez»: la continuidad de la juventud por otros medios. Dicho de otro modo, la(s) juventude(s) se están convirtiendo en un relato sin desenlace, una 
metamorfosis sin fin, colonizando todas las edades. La segunda revolución biográfica, determinada por una transición demográfica hacia el envejecimiento poblacional, es la aparición de la cuarta edad, una sociedad de centenarios aún más excluidos que la tercera edad, que obliga a repensar los dos guetos biográficos conocidos: la juventud y la vejez, y que en el caso de Chile — según los últimos censos y estudios específicos - comienzan a tener progresiva gravitación. Con relación a todo ello, resulta clave esta cifra reciente: cerca del $80 \%$ de las y los jóvenes en Chile viven en casa con sus padres o su familia extensa (Instituto Nacional de la Juventud, 2018) ${ }^{10}$.

En esta dirección, utilizando la misma categoría analítica empleada por Peña, podríamos aventurar otras hipótesis «generacionales» para leer los acontecimientos de octubre y que lejos de ser anomalías - el amplificado e inevitable «conflicto generacional»-, pudiesen ser perfectamente plausibles si, además y como expresaron 240 profesores de su universidad en una carta, evitáramos devaluar a las y los jóvenes como agentes políticos racionales $(E l$ Mostrador, 8 de noviembre de 2019). Por ello, convendría recordar el rol que han jugado los actores juveniles y sus alianzas precisamente en las decisivas transformaciones del país a lo largo del siglo XX. A contrapelo de las horrorizadas monsergas que explicaban las revueltas, «violencias» o perversiones juveniles en las décadas del 20, 50 o 60, por cuestiones de glándulas, carencia de normas o desencuentros generacionales, asistimos varias veces en nuestra historia a la producción de cohortes espacial y biológicamente distantes que han constituido «unidades generacionales autoconscientes» —en el decir de Mannheim (1993 [1928]: 228-229)—, y que a partir de ello, se han reconocido como parte de un colectivo mayor para «agitarse juntos», reaccionar unitariamente. En Chile, por ejemplo, es imposible entender el proceso de mesocratización del país a partir de la década del 20 del siglo pasado, sin conocer el rol clave que jugó la alianza de sectores juveniles emergentes -ácratas, bohemios y «violentos»— con el naciente proletariado (González, 2002). Si bien el movimiento de octubre es un maridaje complejo de clases, capas y «grupos concretos»-transitando con oscilaciones entre los sectores mesocráticos y populares-, es una alianza intergeneracional que se ha ido sellando progresivamente en la medida que la estratificación de la experiencia - habida cuenta de la perseverancia temporal de los elementos más nocivos e intocados

${ }^{10}$ En tanto, la misma encuesta realizada en 2015 arrojó el mismo guarismo, al que debemos sumarle un $9 \%$ que vive en casa de otros familiares como abuelos o tíos (Instituto Nacional de la Juventud, 2015). 
del modelo económico - ha sido constante para sucesivas cohortes de sujetos bisabuelos, - abuelos, padres, hijos, nietos - que desde hace décadas la han padecido juntos, en su vida cotidiana y en la misma casa, imposibilitados - las y los jóvenes, pero también los mayores - de emanciparse residencialmente. De ahí que, aunque podemos reconocer brechas simbólicas - no más profundas que la que acaeció en los 50 y 60 con el surgimiento del rock and roll, la institucionalización del pololeo, el uso de la píldora o la aparición de culturas juveniles revolucionarias - y cadenas de experiencias acusadamente diferenciales en términos de clase o territorio (piénsese en las juventudes rurales o indígenas), se evidencia una conciencia y solidaridad intra e intergeneracional que se profundizan cuando están vertebradas por precariedades que se vivencian en común: desde el endeudamiento educativo, las bajas pensiones, la deplorable cobertura en salud, el hacinamiento o la obligatoriedad de volver a ser joven, en el caso de los mayores (la citada adulescencia), debido al desempleo, el divorcio conyugal o la dependencia económica. Ese fermento social pudiese explicar las multitudinarias expresiones movilizadoras desde 2011 (año en que esta alianza intra e intergeneracional se hace evidente y se consuma) y, claro está, en las marchas en regiones y en Santiago a poco estallar la revuelta de octubre — con más de un millón doscientos mil jóvenes, adultos y viejos-: una comunión transgeneracional inscrita en un modo común de experimentar el hastío y la impotencia. Por ello, aventuramos, no resultan del todo decisivos los «estilos» performáticos, comunicativos o antinormativos para diagnosticar una insoluble brecha entre las nuevas y viejas generaciones y con ello comprender la revuelta. Más bien nos encontramos con un caso ejemplar de «conciencia generacional» (Attius-Donfut, 1991), aquella habilidad de situarse en un tiempo histórico siendo consciente de que existe un pasado y un futuro que va más allá de los límites de la propia existencia y relacionar la propia vida a las de generaciones anteriores y posteriores. ¿Qué es el cancionero del estallido sino la hipérbole de esa conciencia? Líricas y melodías que posibilitan la memoria y voluntad comunicativa entre abuelos, padres e hijos. Dos calendarios distintos, el del curso de la vida y el de la estratificación de la experiencia, se acompasan y, por un momento, el tiempo biográfico e histórico se funden, creando una rebelión multigeneracional. 


\section{Alcances finales}

Por último, cabe aquí esbozar una última reflexión haciendo uso de la misma categoría de análisis de Peña y que nos llevan a coincidir con él al poner el foco en el rol de las generaciones menores en la diacronía y el presente de los hechos de octubre. Si en algo contribuyeron distintivamente las y los jóvenes en la ignición y velocidad de este «estallido», fue la disputa creativa ${ }^{11}$, sostenida por varios años, en el volátil, pero decisivo espacio agonístico de la hegemonía cultural. Aquella zona profunda donde transitan las subjetividades, los síes y noes ontológicos y donde se urden los imaginarios, los supuestos, las visiones y espejismos que limitan o expanden lo que se puede creer, imaginar, cambiar, «quemar» o mantener. Aquel contorno, que había controlado las subjetividades apegadas al consenso de la inmutabilidad o perfectibilidad — nunca una sustitución - del modelo, fue auguralmente colonizado y redibujado en $2011^{12}$, cuando una reivindicación aparentemente sectorial - la gratuidad de la educación superior - modificaba la percepción de lo que era legítimamente posible en términos de destrucción del orden neoliberal: todo. Mientras la agenda del establishment político — incluyendo a las muchas izquierdas - enfatizaba como antes los remiendos (un «nuevo» sistema mixto, una «redefinición» de lo público, mayores becas y subvenciones o baja de aranceles), el movimiento estudiantil del 2011, vigorizado por una mayoría multigeneracional, movió para siempre las fronteras de lo pensable, de lo deliberable y de lo imaginable. Desde entonces y de manera creciente, las élites políticas y económicas fueron perdiendo el control de lo simbólico en la elaboración de los sentidos y los significados de lo que el país es y puede ser.

${ }^{11}$ Ello se cristalizó, en gran medida, en la disputa sobre el carácter público del espacio y en la democratización de la visibilidad como actores sociales. Véase al respecto Urzúa (2015).

${ }^{12}$ Estos hechos permiten concluir a varios investigadores que esta fue una «marca biográfica» fundamental, a tal punto que se puede hablar de una «generación del 2011». Véase Álvarez, Duarte, Garcés y Krauskopf (2016). Más allá, creemos que, aunque estos movimientos erosionaron la hegemonía política y moral de las clases dirigentes y alteraron ciertos imaginarios con relación a otro futuro posible, las élites continuaron «exprimiendo» y capitalizando la lógica del orden, disciplinando y domesticando todas las revueltas juveniles. Así, aunque con un grave déficit de legitimación, el modelo se reacomodaba y se resubjetivaba plásticamente una y otra vez, y ni sus perversiones intrínsecas - pensiones, salud, educación - o los sucesivos escándalos de colusión empresarial parecían amenazar el férreo andamiaje construido en dictadura y solidificado en democracia. 
Durante décadas, el ADN privatizado y privatizador del sistema y su cansino «chorreo» no pudieron resolver los efectos generacionales invariables del modelo neoliberal y las nuevas y mayores demandas, entre otras, un acceso «asequible»a la educación superior, un sólido y equitativo sistema de seguridad social y de salud, salarios acordes al PIB y una autorregulación de la clase empresarial para evitar la hiperexplotación e inequidad, aceptando una mayor carga tributaria. Ello incubó una exasperación social común, acumulativa y «por relevos» en las distintas clases de edad. Sobre la bibliografía que auguraba que el sistema se craquelaría aupado por sus propias contradicciones y limitaciones, algunas autoridades intelectuales mediatizadas - entre ellas el rector Peña y poco a poco una parte importante de la política institucional - parecieron añadir una «narrativa de contingencia» ante los hechos de octubre, de alcances valorativos desde el punto de vista axiológico y sustentado en imperativos políticos eufemizados en credenciales científico-sociales: la modulación paulatina de las transformaciones necesarias — la consabida corrección y autorregeneraciónapuntalada por una sanción «catedrática» de la rebelión a través de una fracción de sus actores expresivos: las y los jóvenes. Dicho relato de contingencia, estructurado y estructurante del etiquetaje, estigma y pánico moral, tuvo un efecto residual que es importante relevar. Permitió, por una vía refleja, catastrar la «conversación social» sobre las y los jóvenes y las dialécticas generacionales para desbrozar lo que está en juego - y en riesgo — para la sociedad mayor. Pero al mismo tiempo y en su conjunto, también reveló ser una potente metáfora, un tropo que señala de manera oblicua pero cierta, que las élites, si bien no perdieron su poder, perdieron su autoridad. Perdieron ese difícil y etéreo consenso que guía las subjetividades y que el 18 de octubre, a partir de una ancha sincronía intergeneracional, vertiginosa, súbita — pero no inesperada—, se les escabulló entre los torniquetes del metro para no regresar.

RECIBIDO: 25 DE NOVIEMBRE DE 2020

ACEPTADO: 14 DE ENERO DE 2021 


\section{BIBLIOGRAFÍA}

\section{Libros y artículos}

Álvarez, C., Duarte, K., Garcés, A. y Krauskopf, D. (2016). Lo generacional como clave para la lectura del Chile actual. Santiago de Chile: Documento de Trabajo Interno.

Attius-Donfut, C. (1991). Générations et ages de la vie. París: PUF.

Calvo, G. (2001). Nacidos para cambiar. Cómo construimos nuestras biografias. Barcelona: Taurus.

CoHen, S. (1972). Folk Devils and Moral Panics. The creation of the Mods and Rockers. Londres: MacGibbon and Kee Ltd.

Comte, A. (1998) [1830-1843]. Cours de philosophie positive (vol. 1-2). París: Hermann.

Dilthey, W. (1989) [1883]. Introduction to the Human Sciences. Princeton: Princeton University Press.

EDmunds, J. y TuRner, B. S. (2002). Generations, Culture and Society. Buckingham: Open University Press

ERIKSON, E. (1950). Childhood and Society. Nueva York: Norton.

FUER, L. (1968). The Conflict of Generations. Londres: Heinemann.

GonzÁlez, Y. (2012). Primeras culturas juveniles en Chile: Pánico, malones, pololeo y matiné. Atenea, 503, 11-38.

. (2002): «Que los Viejos se Vayan a Sus Casas». Juventud y Vanguardia en América Latina. En C. FeIXA, C. Costa y J. R. SAURA, Movimientos Juveniles. De la globalización a la antiglobalización (pp. 59-91). Barcelona: Ariel.

GONZÁLEZ, Y. y FEIXA, C. (2013). La construcción histórica de la juventud en América Latina: bohemios, rockanroleros \& revolucionarios. Santiago de Chile: Cuarto Propio.

Hall, S. (1904). Adolescence: Its Psychology and Its Relations to Physiology, Anthropology, Sociology, Sex, Crime, Religion and Education. Nueva York: D. Appleton \& Co. 
Instituto Nacional DE LA JuVEnTUd. (2019). Encuesta Nacional de Juventud 2018. Santiago de Chile: INJUV.

. (2015). Octava Encuesta Nacional de Juventud. Santiago de Chile: INJUV.

. (2006). Quinta Encuesta Nacional de Juventud. Santiago de Chile: INJUV.

. (2000). Tercera Encuesta Nacional de Juventud. Santiago de Chile: INJUV.

LECCARDI, C. y FEIXA, C. (2014). El concepto de generación en las teorías sobre juventud. En C. FEIXA, De la Generación@ a la \#Generación. La juventud en la era digital (pp. 47-64). Barcelona: NED.

LUTTE, G. (1992). Liberar la adolescencia. Barcelona: Herder.

Mannheim, K. (1993) [1928]. El Problema de las generaciones. Revista Española de Investigaciones Sociológicas, 62, 62-93.

MaríAs, J. (1967). El Método Histórico de las Generaciones. Madrid: Revista de Occidente.

Mead, M. (1970). Culture and Commitment: A Study of the Generation Gap. Nueva York: Natural History Press.

ORTEGA y GASSET, J. (1968) [1923]. El tema de nuestro tiempo. Madrid: EspasaCalpe.

PARSONS, T. (1963). Youth in the context on American Society. En E. ERIKSON, Youth, change and challenge (pp. 93-119). Nueva York: Basik Books.

PeÑA, C. (2020). Pensar el malestar. La crisis de octubre y la cuestión constitucional. Santiago de Chile: Taurus.

URzÚA, S. (2015). ¿Cómo marchan los jóvenes en el Chile de postdictadura? Algunas notas acerca de la apropiación del espacio público y el uso político del cuerpo. Última Década, 42, 39-64.

WeBER, M. (2012). El político y el científico. Madrid: Alianza. 


\section{Prensa}

ELTIT, D. (25 de octubre de 2019). «La revuelta social no puede ser adjudicada a la delincuencia, eso es cómodo e inexacto», entrevista. La Tercera. Recuperado de https://www.latercera.com/culto/2019/10/25/diamelaeltit-revuelta-social/

LA TERCERA. (22 de octubre de 2019). Audio de Cecilia Morel acapara la atención de medios internacionales. Recuperado de https://www.latercera.com/nacional/noticia/audio-de-cecilia-morelmedios-internacionales/872832/

PEÑA, C. (21 de octubre de 2019). «Chile en crisis: Entrevista al analista político Carlos Peña». Canal 13 de televisión. Recuperado de https://www.youtube.com/watch?v=rrtBEuUaDxM\#action=share

. (24 de octubre de 2020). En la crisis, fortalecer el Estado. El Mercurio, cuerpo C, p. 4.

. (27 de octubre de 2019). El nuevo arcoíris. El Mercurio, cuerpo D, p. 11 .

. (1 de noviembre de 2019). El debate en estos días. El Mercurio, cuerpo A, p. 2.

. (1 de diciembre de 2019). Viejas Verdades. El Mercurio, cuerpo D, p. 12.

. (4 de enero de 2020). «No creo haberme equivocado absolutamente en nada», entrevista. La Tercera. Recuperado de https://www.latercera.com/la-tercera-domingo/noticia/carlos-pena-nocreo-haberme-equivocado-absolutamente-nada/961001/

. (10 de noviembre de 2020). La cuestión generacional. El Mercurio, cuerpo A, p. 2.

EL MOSTRADOR. (8 de noviembre de 2019). «A Peña se le mueve el frente interno en la UDP». El Mostrador. Recuperado de https://www.elmostrador.cl/noticias/sin-editar/2019/11/08/a-pena-se-lemueve-el-frente-interno-en-la-udp/ 